\title{
Microangiopathic antiphospholipid syndrome (MAPS) in the course of undifferentiated connective tissue disease
}

\author{
Bożena Targońska-Stępniak, Ewa Wielosz, Maria Majdan \\ Department of Rheumatology and Connective Tissue Diseases, Medical University of Lublin
}

\begin{abstract}
Background. The microangiopathic antiphospholipid syndrome (MAPS) is a subset of APS comprising those patients presenting with thrombotic microangiopathy and demonstrable antiphospholipid antibodies. Renal involvement occurs frequently in the course of MAPS with clinical symptoms of acute renal failure, hypertension, proteinuria and erythrocyturia.

Case report. The report presents the patient with MAPS confirmed by kidney biopsy in the course of undifferentiated connective tissue disease.

Conclusion. The authors emphasize the importance of effective anticoagulant treatment in order to inhibit thrombosis and renal damage in the course of MAPS.
\end{abstract}

Key words: microangiopathic antiphospholipid syndrome, connective tissue diseases, chronic kidney disease, anticoagulant treatment.

\section{Background}

The Antiphospholipid Syndrome (APS) is characterised with recurrent venous and/or arterial thrombosis, obstetric complications and the presence of antiphospholipid antibodies (aPLs) [1]. The APS is considered to be one of the most common systemic connective tissue diseases, as a syndrome with primary character or occurring in the context of other autoimmune diseases (secondary APS) [2]. In 2006 it was proposed that the subset of microangiopathic antiphospholipid syndrome (MAPS) be distinguished, comprising the cases of thrombotic microangiopathy (TMA) with the presence of aPLs [3].

The aim of this paper is to present the case of a patient with MAPS in the course of undifferentiated connective tissue disease.

\section{Case report}

A 51-year-old male patient was first subjected to examination in the Department of Rheumatology and Connective Tissue Diseases in Lublin in July 2009. According to the data obtained from the patient the first symptoms of the disease appeared in February 2008 in the form of brown skin discolorations on his back, then on the skin of chest, abdomen, upper and lower extremities associated with increasing weakness. The patient was not treated before for any cause, he had been a smoker for ca 30 years (15/ day on average). The results of the outpatient laboratory tests conducted in May 2008 confirmed anaemia and elevated ESR level. No significant pathology was found in the skin and lymph node biopsy or in serological tests for viral diseases. Since September 2008 the patient experienced subfebrile body temperatures with periodic fever $\leqslant$ $39^{\circ} \mathrm{C}$ with good response to antipyretics; permanent fever since December 2008. Since October 2008 the elevated arterial blood pressure was observed; since December 2008 body weight loss (3 kg in 2 months), night sweats and cough; since January 2009 elevated serum creatinine and proteinuria. In February 2009 during the business trip abroad the patient experienced significant worsening of his condition with constant fever $>39^{\circ} \mathrm{C}$, hypertension (AH) (systolic > $220 \mathrm{mmHg}$ ), fine-spotted trunk rash and arthralgia (mainly knee and hip joints). The patient was admitted to hospital, Department of Rheumatology 
and Clinical Immunology where the test results showed anaemia (haemoglobin 9.0- $8.2 \mathrm{~g} / \mathrm{dl}$ ) with decreased haptoglobin level $(8 \mathrm{mg} / \mathrm{dl})$ and normal levels of bilirubin and platelets, leukocytosis $(164000 / \mathrm{ll})$, increasing renal function impairment (creatinine 2.2- $3.6 \mathrm{mg} / \mathrm{dl}$, urea 75 $138 \mathrm{mg} / \mathrm{dl}$, cystatin C 3.01- 4.44 mg/l, estimated glomerular filtration (GFR) $34.5-21.9 \mathrm{ml} / \mathrm{min} / 1,73 \mathrm{~m}^{2}$ ), proteinuria and erythrocyturia, elevated concentration of lactate dehydrogenase (LDH) 319-414 U/I and CRP (13,5 mg/ $\mathrm{dl}$ ), decreased complement component C3 (54 mg/dl). The serological tests were negative for: antinuclear antibodies (ANA), anti-cyclic citrullinated peptide (anti-CCP) antibodies, rheumatoid factor (RF), antineutrophil cytoplasmatic antibodys (ANCA); the presence of anti-SS-A/Ro antibodies was detected. The hemolytic-uremic syndrome (HUS) was suspected, for differentiation from thrombotic thrombocytopenic purpura (TTP). The treatment for arterial hypertension (amlodipine and valsartan) and with glucocorticosteroids (GCS) [intravenous (iv) prednisolone at a total dose of $1000 \mathrm{mg}$ followed by oral prednisolone in the dose of $40-30 \mathrm{mg}$ ] was initiated, with which the fever subsided permanently and the articular complaints decreased; packed red blood cells were transfused. The ADAMTS-13 protease activity was determined as 34\% (normal range: 45-110\%) without confirming the low $(<5 \%)$ enzyme activity typical for TTP. Due to persistent symptoms of haemolysis and increasing renal insufficiency the patient was transferred to the Department of Haematology and then to the Department of Kidney Diseases, Hypertension and Rheumatology. The renal biopsy was performed, in the histopatological examination of the biopunctate the features of thrombotic microangiopathy (TMA), diffuse ischemic damage of renal glomeruli, acute tubular necrosis and renal interstitial fibrosis were described; no deposition of immune complexes or complement was detected. The Doppler ultrasound imaging of the renal blood vessels did not confirm their stenosis. Given the high levels of arterial hypertension, symptoms of over-hydration and increasing renal insufficiency (creatinine 6.4-8.0 mg/dl, urea 143-231 mg/dl, eGFR 9.8-7.6 $\mathrm{ml} / \mathrm{min} / 1.73 \mathrm{~m}^{2}$ ), haemodialysotherapy was initiated. The primary suspicion of HUS and TTP was rejected on the basis of mild haemolysis, absence of schistocytes, thrombocytopenia and low ADAMTS-13 levels. The diagnosis of TMA in the course of malignant hypertension or potentially in the course of previously undiagnosed systemic sclerosis (skin changes, narrow lips were described) with renal crisis was made. The treatment with GCS was maintained (prednisolone $20 \mathrm{mg} / \mathrm{d}$, at the attempt of discontinuation the recurrence of fever and joint pain was observed), the treatment for hypertension established (valsartan 160 $\mathrm{mg} / \mathrm{d}$, torasemide $100 \mathrm{mg} / \mathrm{d}$, amlodipine $10 \mathrm{mg} / \mathrm{d}$, metoprolol $95 \mathrm{mg} / \mathrm{d}$ ).

During the patient's treatment in the Department of Rheumatology in Lublin since July 2009 the following were observed: in the physical examination, face skin hardening with the features of microstomia, numerous telangiectasias on the skin of face, chest; oliguria (diurnal urine $500 \mathrm{ml}$ ), arterial hypertension. The immunological tests confirmed the presence of anti-Ro52 and ANA antibodies with granular fluorescence pattern (titre: 1:160) and IgG anti- $\beta_{2}$ glycoprotein-I (anti- $\beta_{2} \mathrm{GP}-\mathrm{I}$ ) antibodies (46.55 SGU, positive result $>20$ ). The presence of ANCA, anticardiolipin $(\mathrm{aCL})$ antibodies, lupus anticoagulant (LAC) was not detected. In the contrast examination of the upper gastrointestinal tract the esophageal motility abnormalities were not found. The capillaroscopy demonstrated slight disorganisation of microvascular array, however without the features of scleroderma microangiopathy. In the high-resolution computer tomography (HRCT) of the chest no interstitial changes or features of pulmonary embolism were found. The pulmonary function tests showed the preserved diffusion capacity and lung volumes. In the ECG, slight reduction of the ejection fraction (59\%) and increased pulmonary artery pressure (PASP $37 \mathrm{mmHg}$ ) were observed. In the salivary gland scintigraphy the functional disorders of submandibular glands were observed; negative Schirmer's test.

Based on data collected from the medical history and the results of biochemistry, serological, histopathological (including kidney biopsy) and imaging tests the thrombotic microangiopathy (TMA) was diagnosed which in the presence of anti-GP-I antibodies has the form of the microangiopathic antiphospholipid syndrome (MAPS) in the course of undifferentiated connective tissue disease.

The decision was taken on the introduction of anticoagulant therapy with an oral anticoagulant (warfarin) and with the inhibitor of platelet aggregation (clopidogrel). The dose of GCSs was reduced (prednisone $5 \mathrm{mg} / \mathrm{d}$, since February $20102.5 \mathrm{mg} / \mathrm{d}$ ) and the cyclophosphamide therapy was initiated $(400 \mathrm{mg}$ in intravenous infusions every 3-4 weeks; then after the total dose achieved 5800 mg, every three months). In the treatment for arterial hypertension and as a cardiovascular protective therapy, angiotensin convertase inhibitors were introduced (enalapril 25-40 mg/d, with partial replacement with cilazapril due to dry cough), amlodipine was replaced with verapamile $160 \mathrm{mg} / \mathrm{d}$, and statin was added (simvastatin $20 \mathrm{mg} / \mathrm{d}$ ).

As the result of the applied treatment the proper control of the arterial hypertension, permanent diure- 
sis $(2000-3000 \mathrm{ml} / \mathrm{d})$ and stabilisation of the renal function with reduced frequency of haemodialysis, less severe skin changes were obtained.

\section{Discussion}

The case presented herein illustrates the problem of early diagnosis and initiation of treatment for MAPS developing in the course of undifferentiated connective tissue disease. The thrombotic microangiopathic changes described in the histopatologic examination of kidney biopunctate together with the presence of anti- $\beta_{2} \mathrm{GP}-\mathrm{I}$ antibodies allow making the MAPS diagnosis. The early initiation of anticoagulant therapy would have probably enabled the inhibition of the thrombotic process and maintaining the renal function.

The thrombotic process in the course of APS often involves kidneys and the clinical symptoms depend on the renal vascular calibre and activity of the thrombotic process [2, 4-5]. One of the forms of renal involvement in the course of APS is the APS nephropathy resulting from the thrombotic microangiopathic changes in small renal blood vessels and glomeruli with the absence of immune deposits or inflammatory cells (small vessel occlusive disease) [2, 4-5]. The symptoms of APS nephropathy include arterial hypertension (in nearly all patients), reduced GFR with potential acute renal failure, proteinuria and erythrocyturia. The best diagnostic method is the renal biopsy; it is, however, rarely performed due to the concomitant anticoagulant therapy [2, 4-5].

The thrombosis of small blood vessels (e.g. in kidney, retina, skin, lungs, liver or intestine) is the vital part of the clinical picture of APS. In 2006 the subset of APS termed MAPS was distinguished; it covers the cases of classic primary autoimmune diseases (e.g. systemic lupus) with TMA, but without the obstruction of large blood vessels $[3,6-9]$. The MAPSs include also thrombotic thrombocytopenic purpura (TTP), hemolytic-uremic syndrome (HUS), HELLP obstetric syndrome, catastrophic APS (CAPS), provided that the symptoms of large blood vessel obstruction do not appear [2-3, 6-9]. These are syndromes where the TMA features are found in the microcirculation in various organs and the occurrence of aPLs is observed, probably induced by the damage of the blood vessel endothelium [7]. The symptoms in such patients appear upon the activation of usually similar factors (infections, drugs, pregnancy) and are similar (haemolytic anaemia, thrombocytopenia, acute renal failure).

The MAPS management is conducted on the basis of scarce experience from clinical observations given the lack of international guidelines [4]. It is based on the successful lifelong treatment for arterial hypertension and anticoagulant therapy, aiming at stopping the process of renal failure $[2,5]$. The treatment depends also on finding whether the MAPS occurs in the course of primary APS or another autoimmune disease. In the case of systemic disease, the treatment based on GCSs or complementary immunosuppressive therapy may be indicated, depending on the activity of primary disease $[2,4]$. It has been suggested recently that the aPLs have pathogenic effect not only on the haemostatic system but also activate the complement system and increase the inflammatory condition leading to tissue damage [4, 10]. For these reasons, getting under control simultaneously the thrombotic and inflammatory process seems to be of particular advantage for these APS patients [4].

\section{References}

1. Miyakis S, Lockshin MD, Atsumi T et al. International consensus statement on an update of the classification criteria for definite antiphospholipid syndrome (APS). J Thromb Haemost. 2006;4:295-306.

2. Majdan M. Zespół antyfosfolipidowy a choroba nerek. PolMerk Lek. 2010;28:341-4.

3. Asherson RA. New subsets of the antiphospholipid syndrome in. 2006: „PRE-APS” (probable APS) and microangiopathic antiphospholipid syndromes ("MAPS"). Autoimmun Rev. 2006;6:76-80.

4. Tektonidou MG. Renal involvement in the antiphospholipid syndrome (APS)-APS Nephropathy. Clin Rev Allerg Immunol. 2009;36:131-40.

5. Majdan M. Nerki a zespół antyfosfolipidowy. Pol Arch Med Wewn. 2007;117(Supl):55-8.

6. Asherson RA, Cervera R. Microvascular and microangiopathic antiphospholipid-associated syndromes ("MAPS"): semantic or antisemantic? Autoimmun Rev. 2008;7:164-7.

7. Asherson RA, Pierangeli SS, Cervera R. Is there a microangiopathic antiphospholipid syndrome? Ann Rheum Dis. 2007;66:429-32.

8. Asherson RA, Pierangeli S, Cervera R. Microangiopathic antiphospholipid-associated syndromes revisited new concepts relating to antiphospholipid antibodies and syndromes. J Rheumatol. 2007;34:1793-5.

9. Praprotnik S, Ferluga D, Vizjak A et al.: Microthrombotic/ microangiopathic manifestations of the antiphospholipid syndrome. Clin Rev Allergy Immunol. 2009;36:109-25.

10. Salmon JE, Groot PG. Pathogenic role of antiphospholipid antibodies. Lupus. 2008;17:405-11.

Correspondence address: Bożena Targońska-Stępniak Department of Rheumatology and Connective Tissue Diseases 8 Jaczewskiego Street 20-950 Lublin, Poland email: bozena.stepniak@am.lublin.pl 